\title{
Time and motion study of a cashew nut processing factory in Dapoli
}

AMIT A. DEOGIRIKAR, V.V. AWARE AND R.V. POWAR

Received : 27.05.2017; Revised : 03.09.2017; Accepted : 19.09.2017

See end of the Paper for authors' affiliation

Correspondence to :

AMIT A. DEOGIRIKAR

Department of Farm Power and Machinery, College of Agricultural Engineering and Technology, Dr Balasaheb Sawant Konkan Krishi Vidyapeeth, Dapoli, RATNAGIRI (M.S.) INDIA Email : amitdeogirikar @ rediffmail.com
ABSTRACT : Cashew is the one of the major horticultural crops in the Konkan Region of Maharashtra. Hence, the cashew processing industries are having good scope in this region. The usual trend is that the entrepreneurs here start their cashew processing unit on small scale and with the availability of funds they expand their unit. Hence, there is no logical expansion of the processing plants occur that ultimately add to the processing cost. The processing units which are set with proper planning can save time and motion and the cost of processing. This article presents the time and motion study of two cashew processing units one of which is gradually expanded while the other one is set up with proper planning. A theoretical attempt is made to improve the planning of the gradually expanded unit to reduce the time and motion.

- KEY WORDS : Cashew nut processing, Time motion study, Layout, Distance

- HOW TO CITE THIS PAPER : Deogirikar, Amit A., Aware, V.V. and Powar, R.V. (2017). Time and motion study of a cashew nut processing factory in Dapoli. Internat. J. Agric. Engg., 10(2) : 581589, DOI: 10.15740/HAS/IJAE/10.2/581-589. 